\title{
A PRODUÇÃO DO ESPAÇO JURÍDICO-POLÍTICO DA CIDADE: UMA ABORDAGEM A PARTIR DA TEORIA DE HENRI LEFEBVRE
}

\section{THE PRODUCTION OF THE CITY'S LEGAL-POLITICAL SPACE: AN APPROACH FROM HENRI LEFEBVRE'S THEORY}

\author{
Idir Canzi $i^{1}$ \\ Marcelo Markus Teixeira ${ }^{2}$
}

\section{Resumo}

O artigo versa sobre a produção do espaço jurídico-político da cidade, na perspectiva do referencial teórico de Henri Lefebvre. A contribuição é teórica e não empírica. O estudo, ao retomar elementos da análise de Lefebvre, pretende dimensionar e problematizar a história do espaço jurídico-político da cidade antiga, medieval e moderna no contexto da Europa. Neste sentido, o nascimento e a expansão da indústria, que se conecta com o modo de desenvolvimento da vida urbana, fez implodir o centro de referência político da cidade antiga e desequilibrou o modo de produção do espaço das cidades medievais, em que tudo circulava e se voltava ao desenvolvimento local da própria cidade e seu entorno. Os aspectos jurídicos e políticos não se apresentam dissociados do espaço geográfico e do contexto social articulado ao modo de produção vigente num determinado tempo e espaço. $O$ direito à cidade possui relação direta com o acesso e o valor de uso da cidade. A produção do espaço é social. É condição, meio e produto das relações sociais. A cidade é uma das qualificações do espaço geográfico. Trata-se de pesquisa bibliográfica, pautada pela utilização do método dedutivo, a partir da análise de artigos, periódicos e livros.

Palavras-chave: Produção do Espaço; Cidadania; Direito à Cidade; Espaço Jurídico-Político; Valor de Uso.

\begin{abstract}
The article analyzes the production of the juridical-political space of the city, in the perspective of the theoretical reference of Lefebvre. The contribution is theoretical and not empirical. The study, when retaking elements of the analysis of Lefebvre, intends to dimension and to problematize the history of the juridical-political space of the old, medieval and modern city in the context of Europe. In this sense, the birth and expansion of industry, which connects with the development of urban life, has imploded the center of political reference of the ancient city and has imbalanced the mode of production of the space of medieval cities, where everything circulated and it turned to the local development of the city itself and its surroundings. The legal and political aspects are not dissociated from the geographic space and the social context articulated to the current mode of production in a given time and space. The right to the city has a direct relation with the access and the use value of the city. The production of space is social. It is the condition, medium and product of social relations. The city is one of the qualifications of geographical space. The research is bibliographical, based on the use of the deductive method, from the analysis of articles, periodicals and books.
\end{abstract}

\footnotetext{
${ }^{1}$ Doutor em Direito Internacional pela UFSC. Docente do Curso de Direito da Unochapecó. E-mail: canzi@unochapeco.edu.br

${ }^{2}$ Doutor em Direito Internacional Privado pela Universität zu Köln (Alemanha). Professor permanente do Programa de Mestrado em Direito Acadêmico da Unochapecó. E-mail: marcelomarkus@unochapeco.edu.br
} 
Keywords: Production of Space; Citizenship; Right to the City; Legal-Political Space; Use Value.

\section{INTRODUÇÃO}

O conteúdo do artigo centra seu objetivo em analisar e problematizar sobre a produção do espaço jurídico-político da cidade antiga, o modo equilibrado do valor de uso com o valor de troca que alimentou e tornou interessante a vida das cidades comerciais medievais na Europa, sem perder o assento sobre a abordagem da cidade moderna, imersa no contexto industrial e da urbanização. O marco teórico é a "produção do espaço" de Henri Lefebvre. O trabalho da pesquisa justifica-se pelo objeto de estudo sobre a cidade, a qual envolve diferentes áreas de interesse, entre estas a sociologia, a história, a ciência política, a geografia e o Direito.

A importante e inovadora teoria dialética ${ }^{3}$ da produção do espaço de Henri Lefebvre amplia as abordagens contemporâneas do conhecimento e do próprio Direito, vinculativas da realidade espaço-temporais da realidade social. Lefebvre não procura analisar e isolar os elementos da produção do espaço. Suplanta a visão redutiva do conceito de espaço de modo a ampliar as análises sobre a produção e reprodução social do espaço, notadamente do espaço urbano, imbricado na complexidade das cidades no contexto industrial e da urbanização, da sociedade capitalista globalizada.

Para Lefebvre o espaço faz parte das forças e meios de produção. É produto dessas mesmas relações. É parte essencial desse processo. O espaço tornou-se, para o Estado, um instrumento político de importância capital. O Estado usa o espaço de forma que assegura seu controle de lugares, sua hierarquia estrita, a homogeneidade do todo e a segregação de partes (GOTTDIENER, 1993, p. 129-130). Ao afirmar que o espaço não existe em "si mesmo" e que o espaço é produzido, Lefebvre compreende o espaço como categoria analítica que o pensamento permanece em sua dimensão abstrata e, como produto social, desvela-se no realconcreto. (LEFEBVRE, 2006, p. 03-10).

A cidade, o espaço urbano e a realidade urbana não podem ser concebidos apenas

\footnotetext{
3 Lefebvre desenvolveu uma versão altamente original da dialética baseada no seu continuado engajamento crítico com Hegel, Marx e Nietzsche; três pensadores Alemães que influenciaram centralmente a configuração de sua teoria. (SCHMIDT, 2012, p. 89-102). "Dialética era, na Grécia antiga, a arte do diálogo. Aos poucos, passou a ser a arte de, no diálogo, demonstrar uma tese por meio de um argumentação capaz de definir claramente os conceitos envolvidos na discussão. Na concepção moderna, entretanto, dialética significa outra coisa: é o modo de pensarmos as contradições da realidade, o modo de compreendermos a realidade como essencialmente contraditória e em permanente transformação". (KONDER, 2008, p. 8).
} 
como locais de produção e consumo:

O espaço não é apenas econômico. Onde todas as partes são intercambiáveis e tem valor de troca. O espaço não é apenas político para homogeneizar todas as partes da sociedade. Ao contrário... O espaço continua sendo um protótipo permanente do valor de uso que se opõe às generalizações do valor de troca na economia capitalista sob a autoridade de um Estado homogeneizador. O Espaço é um valor, mas ainda assim é tempo ao qual ele está, em última análise, vinculado, porque tempo é nossa vida, nosso valor de uso fundamental. O tempo desapareceu no espaço social da modernidade (LEFEBVRE, 1993, p. 132).

A sociedade industrial e da urbanização provocou a divisão e reivindicação ativa de espaço ${ }^{4}$ por uma multidão de atores e instituições de modo que produziu uma "explosão de espaços" - a articulação múltipla das relações sociais estratificadas com o espaço. Espaços contraditórios, com dimensionalidades ${ }^{5}$ que ultrapassam as fronteiras do conflito socioespacial, de modo a tornar aparente os interesses de pessoas e grupos da sociedade.

A juridicidade integra a própria concepção de produção do espaço de Lefebvre, presente nas atividades da prática social, representações do espaço e espaços de representação, diretamente interconectados na produção do espaço. A normatividade é ao mesmo tempo constitutiva e resultante do ambiente produzido, da organização, da orientação e da co-determinação das atividades. Para Lefebvre, a juridicidade integra a ordem espacial das relações sociais de produção e concorre para o controle das contradições, em benefício dos interesses predominantes na sociedade e seu modo de produção (GOTTDIENER, 1993, p.128). O direito à cidade, à vida urbana, diferente da urbanização, assume uma condição de humanismo e de democracia renovados. O direito à cidade possui relação direta com o acesso e do valor de uso da cidade. A urbanização no processo industrial da sociedade capitalista privilegia o valor de troca em descaracterização ao urbano, da reunião, da convergência, dos encontros (LEFEBVRE, 2006, p. 81). A urbanização serve e impulsiona a reprodução das relações sociais de produção realizadas para responder aos processos oriundos das formas dos capitais se reproduzirem.

Em sua obra ${ }^{6}$ o Direito à Cidade, Lefebvre afirma que a cidade preexiste à

\footnotetext{
4 "O fato de que os eventos sejam ao mesmo tempo espaciais e temporais não significa que não se pode interpretá-los fora de suas próprias determinações ou sem levar em conta a totalidade da qual eles emanam e que eles reproduzem. O espaço social não pode ser explicado sem o tempo social". (SANTOS, 2008, p.253).

${ }^{5}$ Espaço vivido, espaço pessoal, espaço escolástico, espaço de prisão, espaço de exército. Espaço de hospital, espaço da cidade, espaço das relações sociais.

${ }^{6}$ Entre as obras de Lefebvre encontram-se: A Produção do Espaço, O Direito à Cidade, A Reprodução das Relações de Produção, Espaço e Política, A Revolução Urbana, entre outras. David Harvey, Mark Gottdiener, Manuel Castells, Milton Santos e Ani Fani Alessandri Carlos integram o rol de autores com
} 
industrialização e que as cidades são centros da vida social e política onde se acumulam não apenas as riquezas como também os conhecimentos, as técnicas e as obras (LEFEBVRE, 2006, p. 04). Registra-se aqui que é possível considerar que o direito à cidade, sob os termos da urbanização no presente, realiza em parte os conteúdos abordados por Lefebvre, notadamente nas cidades menores, com melhor estruturação e efetividade dos instrumentos da política urbana e das funções sociais da cidade, a exemplo do plano diretor, regularização fundiária, saneamento, acesso à moradia adequada, entre outros.

A dialética tridimensional de Lefebvre interconecta as dimensões dos conceitos "prática espacial, "representação do espaço" e "espaços de representação", melhor delineados a seguir com a abordagem sobre a produção do espaço, relacionado com a temática da cidade política, comercial, industrial e da urbanização ${ }^{7}$ no contexto da sociedade do capital.

\section{A PRODUÇÃO DO ESPAÇO}

A teoria da produção do espaço de Lefebvre constitui uma epistemologia de fundamentos que contempla os contextos espaciais em diferentes níveis ${ }^{8}$, vinculativos também dos aspectos jurídico-político.

Lefebvre parte do referencial que o espaço é produzido socialmente. O desenvolvimento de sua teoria vincula o conceito relacional de espaço e tempo. O espaço representa simultaneidade, a ordem sincrônica da realidade social. O tempo corresponde ao processo histórico da produção social. Consigna-se aqui que o espaço é categoria analítica de Lefebvre.

Espaço e tempo são entendidos como produtos da prática social, resultado e précondição da produção da sociedade (relação entre os seres humanos por meio de suas atividades práticas). Por conseguinte, como espaço e tempo são produzidos socialmente, só podem ser compreendidos no contexto de uma sociedade específica. Tal assertiva implica que o espaço e tempo são relacionais e históricos.

A compreensão da produção do espaço demanda uma análise para além dos fatores materiais e capaz de considerar as redes sociais, relações de poder e conflitos implicados em

pesquisas relacionadas a temática da produção do espaço social, considerados de certa forma seguidores de Lefebvre, e/ou, contrapontos da referida teoria.

7 Referida abordagem vincula o ponto crítico da problemática da cidade, suscitado por Lefebvre, a partir da cidade industrial que assume o duplo processo (industrialização e urbanização).

${ }^{8}$ Do global ao local, sem exclusão da ligação relacional das diferentes áreas do conhecimento, ou seja, do social, político, econômico, jurídico, ambiental e cultural. 
cada situação, inserindo também a representação do espaço e espaço de representação.

A pergunta que não quer calar é como o espaço (social) é produzido? A produção do espaço pode ser dividida em três dimensões (também chamadas de formantes ou momentos da produção), a saber: prática espacial, representações do espaço e espaços de representação ${ }^{9}$. Tais dimensões se referem ao espaço também percebido, concebido e vivido ${ }^{10}$, compreensíveis no conjunto da obra de Lefebvre.

Nesta perspectiva, a análise tridimensional da produção do espaço é descrita na obra de Lefebvre da seguinte forma:

A prática espacial, que engloba produção e reprodução, lugares especificados e conjuntos espaciais próprios de cada formação social, que assegura a continuidade numa relativa coesão. Essa coesão implica, no que concerne ao espaço social e à relação de cada membro de determinada sociedade ao seu espaço, ao mesmo tempo de uma competência certa e uma certa performance; As representações do espaço, ligadas às relações de produção, à "ordem" que elas impõem e, desse modo, ligadas ao conhecimentos, aos signos, aos códigos, às relações "frontais"; Os espaços de representação, apresentam (com ou sem códigos) simbolismos complexos, ligados ao lado clandestino e subterrâneo da vida social, mas também à arte que eventualmente poder-se-ia definir não como código do espaço, mas como código de representação (LEFEBVRE, 2000, p. 36).

Portanto, o espaço (social) vincula o ambiente construído, a organização, a orientação e

co-determina as atividades, ao mesmo tempo que pode resultar na expressão de valores, normas e experiências sociais:

O espaço social "incorpora" atos sociais, os dos sujeitos ao mesmo tempo coletivos e individuais, que nascem e morrem, padecem e agem. [...]

\footnotetext{
${ }^{9}$ A dialética tridimensional da teoria da produção do espaço de Lefebvre congrega os seguintes momentos interconectados: prática social material (Marx); Linguagem e pensamento (Hegel) e o ato criativo, poético (Nietzche).

${ }^{10}$ A tríade espaço percebido, espaço concebido e espaço vivido é, ao mesmo tempo, individual e social; não é somente constitutiva da autoprodução do homem, mas da autoprodução da sociedade. Todos os três conceitos denotam processos ativos individuais e sociais ao mesmo tempo. Espaço percebido: o espaço tem um aspecto perceptível que pode ser apreendido por meio dos sentidos. Essa percepção constitui um componente integral de toda prática social. Ela compreende tudo o que se apresenta aos sentidos; não somente a visão, mas a audição, o olfato, o tato e o paladar. Esse aspecto sensualmente perceptivo do espaço relaciona-se diretamente com a materialidade dos "elementos" que constituem o "espaço". Espaço concebido: o espaço não pode ser percebido enquanto tal sem ter sido concebido previamente em pensamento. A junção de elementos para formar um "todo" que é então considerado ou designado como espaço presume um ato que é ligado à produção do conhecimento. Espaço vivido: a terceira dimensão da produção do espaço é a experiência vivida do espaço. Essa dimensão significa o mundo assim como ele é experimentado pelos seres humanos na prática da sua vida cotidiana. Neste ponto Lefebvre é inequívoco: o vivido, a sua experiência prática, não se deixa exaurir pela análise teórica. Sempre permanece um excedente, um remanescente, um indizível, o que não é passível de análise apesar de ser o mais valioso resíduo, que só pode ser expresso por meio de meios artísticos. (SCHMIDT, 2012, p. 89-109).
} 
Gerar (produzir) um espaço social apropriado trata-se de um processo. [...]. O espaço social é o da sociedade. O espaço envolve o tempo. Cindese-o: descarta o tempo. Através do espaço um tempo social se produz e reproduz; mas esse tempo social se reintroduz com seus traços e determinações: repetições, ritmos, ciclos e atividades (LEFEBVRE, 2000, p. 36-37).

Nunca é demasiado afirmar que para Lefebvre o espaço faz parte ${ }^{11}$ das forças e meios de produção. É produto e processo dessas mesmas relações sociais de produção e reprodução.

Na perspectiva do espaço como produção social, prossegue-se com a inserção da temática da cidade política, da cidade comercial e do valor de uso, da cidade industrial e da urbanização.

\section{A CIDADE POLÍTICA}

Para Lefebvre a cidade preexiste à industrialização e constitui-se em centro da vida social e política (LEFEBVRE, 2006, p. 04).

A produção do espaço da cidade política a qual Lefebvre se refere é a da cidade-Estado, com especificidade exemplificativa das atividades da prática espacial ligadas à realidade das cidades Gregas e de Roma.

A especificidade das cidades-Estado Gregas e de Roma, resultantes da reunião de várias aldeias ou tribos estabelecidas num território, permitiu o desenvolvimento da divisão do trabalho e da propriedade mobiliária (dinheiro) sem destruição da propriedade coletiva ou antes "comunitária" do solo (LEFEBVRE,2006, p. 28). Não se pode esquecer que nas referidas cidades havia uma minoria de livres cidadãos com poderes sobre os outros membros da cidade: mulheres crianças, escravos e estrangeiros.

A cidade estabelecia a ligação de seus elementos associados à forma de propriedade comunal ("propriedade privada comum" ou "apropriação primitiva") dos cidadãos ativos, os quais se opõem aos escravos (LEFEBVRE,2006, p.28). A forma associativa na ordenação da cidade-Estado constituía uma democracia, porém, com elementos estreitamente hierarquizados e submetidos às exigências da cidade.

Lefebvre destaca que "no transcorrer da história da cidade Estado, a propriedade privada pura e simples (do dinheiro, do solo, dos escravos) se fortalece, sem abolir os direitos

${ }^{11}$ Observa-se que para Lefebvre, muito diferente dos economistas políticos marxistas (concepção de espaço apenas ao ambiente construído), as propriedades da dialética das relações espaciais se articulam com as propriedades das relações exteriorizadas do modo de produção em inúmeros níveis. (GOTTDIENER, 1993, p. 128). 
da cidade sobre o território" (LEFEBVRE, 2006, p. 28).

A divisão do trabalho retratada na República de Platão ${ }^{12}$ e na Política de Aristóteles $^{13}$, aparecem descritas na concepção de Lefebvre na separação entre cidade e campo, como as primeiras e fundamentais divisões do trabalho. Tratava-se de uma divisão do trabalho conforme os sexos e idades (divisão biológica e técnica). Nas palavras de Lefebvre:

A divisão social do trabalho entre cidade e campo corresponde à separação entre trabalho material e trabalho intelectual, e, por conseguinte, entre o natural e o espiritual. À cidade incumbe o trabalho intelectual: funções de organização e de direção, atividades políticas e militares, elaboração do conhecimento teórico (filosofia e ciências). A totalidade se divide; instauram-se separações, inclusive a separação entre Physis e o logos, entre teoria e a prática e, na prática, as separações entre práxis (ações sobre os grupos humanos), poiéses (criação de obras), tchné (atividade armada com técnicas e orientada para os produtos). O campo, ao mesmo tempo realidade prática e representação, vai trazer imagens da natureza, do ser, do original. A cidade vai trazer as imagens do esforço, da vontade, da subjetividade, da reflexão, sem que essas representações se afastem de atividades reais. Dessas imagens confrontadas vão nascer grandes simbolismos. Ao redor da cidade Grega, acima dela, dispõe-se o cosmos, espaços ordenados e luminosos, hierarquia de lugares (LEFEBVRE , 2006, p. 28-29).

Na referida citação resta evidenciada a concepção da produção tripartite do espaço na concepção de Lefebvre: as atividades da prática espacial (relações entre seres humanos em suas atividades de produção da vida e da cidade), as representações do espaço (campo-cidade com correspondente divisão do trabalho) e espaços de representação ligados ao simbolismo e significados de tudo o que emerge da ação humana no espaço produzido/vivido da cidade política. Ainda, nesse sentido, o próprio Lefebvre destaca que:

na cidade grega triunfa, não sem lutas o espírito apoliniano, o símbolo luminoso da razão que coordena; em compensação, na cidade etruscoromana triunfa o lado demoníaco do urbano. O filósofo não admite a separação; não concebe que o mundo, a vida, a sociedade, o cosmos (e mais tarde a história) possam não mais constituir um todo. A filosofia, portanto, nasce da cidade, com a divisão do trabalho e suas modalidades múltiplas. (LEFEBVRE, 2006, p.29).

Denota-se claramente que o logos da cidade grega não encontrava-se separado do logos filosófico, atento em não fracionar na linguagem a totalidade da vida urbana e a vida da

\footnotetext{
${ }^{12}$ A República é uma descrição da melhor forma de Constituição; O político é uma investigação, estudo e descrição do melhor tipo de governante - o rei filósofo, que possui a ciência do Bom governo. O ReiFilósofo estaria ao centro da cidade, os trabalhadores produtivos produziriam a alimentação e vestuário a partir do entorno da cidade, os guerreiros (cidadãos de posse de armas) ficariam encarregados de conferir proteção à cidade. Platão viveu na época da decadência da gloriosa democracia ateniense e seus escritos examinam, analisam e denunciam a degradação da Pólis. (PLATÃO, 2014; BOBBIO, 1994, p. 53).

13 "A Constituição é a estrutura que dá ordem à cidade, determinando o funcionamento de todos os cargos públicos e sobretudo da autoridade soberana" (1278b). (ARISTÓTOLES, 2009; BOBBIO, 1994, p.55).
} 
cidade com suas riquezas, conhecimentos, técnicas e obras.

A cidade política tinha seu centro organizacional forte representados em seus monumentos e lugares (ágora, acrópole). Havia a plenitude do espaço político (aquele da cité da Cidade-Estado) instaurado no espaço natural (LEFEBVRE, 2000, p. 47).

Não se trata de localizar no espaço preexistente uma necessidade ou uma função, mas, ao contrário, trata-se de espacializar uma atividade social, ligada a uma prática no seu conjunto, produzindo um espaço apropriado (LEFEBVRE, 2008, p. 150).

Em sua obra $O$ direito à cidade, Lefebvre volta sua análise na direção da entrada para a prática do direito à vida urbana, sem prescindir da condição humanista e da defesa de uma democracia renovadas.

Lefebvre vai além da historicidade apresentada da cidade-Estado! Vai buscar na já anunciada dialética tridimensional os argumentos para estabelecer a crítica à produção do espaço na teia das relações sociais de produção e re-produção (LEFEBVRE , 1973) das relações de produção na sociedade industrial e do capitalismo, porém, sem deixar de adentrar na análise antecedente da produção da cidade comercial da idade média.

\section{A CIDADE COMERCIAL E DO VALOR DE USO}

Produção do espaço comercial e valor de uso são as duas categorias centrais de análise que delineiam a abordagem do presente tópico sobre as cidades medievais, em seguimento à teoria da produção do espaço de Lefebvre:

A noção e a imagem do centro comercial datam de fato da Idade Média. Corresponde a pequena e média cidade medieval. Mas hoje o valor de troca prevalece a tal ponto sobre o valor de uso que quase suprime este último (LEFEBVRE, 2006, p. 13).

A produção do espaço comercial do renascimento das cidades na idade média diferencia-se significativamente do espaço da sociedade industrial produzido na modernidade, objeto da abordagem subsequente.

A história registra que com o declínio do Império Romano ocorreu também a derrocada das cidades ocidentais, dando lugar a propriedade feudal do solo, com servos no lugar dos escravos. Dissolveu-se a relação cidade, propriedade e relações de produção no modo vigente até então ${ }^{14}$.

\footnotetext{
14 "O período medieval caracterizou-se pela preponderância do feudalismo, estrutura econômica, social, política e cultural que se edificou progressivamente na Europa-Centro-Ocidental em substituição à estrutura escravista da antiguidade romana. O feudalismo começou a se formar no final do Império
} 
Quanto a produção do espaço no contexto do renascimento das cidades na Idade Média, Lefebvre teoriza que:

com o Renascimento das cidades, há por um lado organização feudal da propriedade e da posse do solo (as comunidades camponesas têm uma posse costumeira e os senhores a posse "eminente", como mais tarde se dirá) e por outro lado uma organização corporativa das profissões e da propriedade urbana. Ainda que no princípio dominada pela propriedade senhorial do solo, esta dupla hierarquia contém a condenação dessa propriedade e da riqueza imobiliária. Donde um conflito profundo, essencial para a sociedade medieval. "A necessidade de se associar contra os cavaleiros saqueadores (estes mesmos associados), a necessidade de mercados comuns numa época em que o industrial era artesão, a concorrência dos servos em liberdade condicional, servos que acorriam para as cidades cujas riquezas aumentavam, a organização feudal inteira fez nascer as corporações. Os pequenos capitais lentamente economizados por artesãos isolados e seu número estável o meio de uma população crescente desenvolveram o sistema de companheiros e aprendizes; coisa que estabeleceu nas cidades uma hierarquia semelhante à dos campos (LEFEBVRE, 2006, p. 31).

Para Lefebvre a cidade tem uma história e sempre manteve as relações com a sociedade em seu conjunto, composição e funcionamento.

Na Idade Média, a cidade era concentrada em pequeno espaço, lugar mesclado de produção e de trocas comerciais fortalecidas por uma economia monetária gradual que estimulou um novo sistema de valores, trabalho, comércio e dinheiro. Havia um ideal de igualdade e ao mesmo tempo de divisão social da cidade. O fortalecimento no século XIV de grandes corporações e mercadores aliados conferiu maior poder comercial e local às cidades (LE GOFF, 1998, p. 25).

Le Goff também identifica o período da Idade Média Central (séculos XI-XIII) com o apogeu do desenvolvimento do feudalismo no âmbito da produção rural e de fortalecimento da expansão comercial no âmbito da economia de mercado, marcos da retomada da vida urbana, aumento da população e cidades (LE GOFF, 1998, p. 54).

Para Grossi:

A cidade é, portanto nesse segundo período medieval, um extraordinário laboratório consuetudinário e ativo eficiente. O costume citadino, é para

Romano do Ocidente e das invasões bárbaras, alcançando o seu apogeu no final da Idade Média, período compreendido entre os séculos $V$ e $X$. O declínio do feudalismo, que já se esboçava no século $X$, prosseguirá até o século XV, constituindo o período convencionalmente chamado de Baixa Idade Média. Não é raro encontrarmos a expressão Idade Média Central, referente ao período do apogeu feudal, situado entre os séculos VII e o XIII, aproximadamente. Após 476, com a ruína de Roma e o fim do escravismo, a população deixou as cidades, buscando sobrevivência no campo. A agricultura, praticada nas vilas (grandes propriedades agrárias), constituiu a base de uma economia autossuficiente, cujos desdobramentos conduziram à formação do mundo agrário-feudal". (VICENTINHO,1997. p. 107). 
cada civitas, mais que um instrumento para regular as relações jurídicas; é com efeito, um instrumento político, pois indica uma relativa autonomia no âmbito do grande invólucro imperial (GROSSI, 2014, p. 225).

Destaca-se que o movimento e/ou luta existente, à época acima referida, era centralmente em defesa de uma iurisdictio autônoma, simbolizada no conjunto de normas consuetudinárias (GROSSI, 2014, p. 225). O costume ${ }^{15}$ ensejava a prática social espacial das atividades e comportamento.

As atividades da prática espacial de comércio existentes nas cidades da Idade Média produziram uma nova realidade social, uma relação (dialética) no espaço, a partir de sua história. O espaço produzido surge como relação espacial engendrada entre o urbano e o ruralcidade e campo. O espaço-social se produz e se reproduz em conexão com as forças produtivas (e as relações de produção). (LEFEBVRE, 2006, p. 69-70). Lefebvre exemplifica que foi o trabalho social que transformou a Toscana a partir do século XIII ${ }^{16}$.

O espaço-social produzido e reproduzido na referida relação espacial engendrada entre o urbano e o rural - cidade e campo, no contexto das cidades medievais, insere características que revelam certa oposição entre o valor de uso e o valor de troca. A oposição entre o valor de

15 "O costume é um comportamento repetido na conviç̧ão de que seja bom comportar-se assim. Essa definição é mais ampla do que a aceita pelos juristas, porque o costume é um fato social que se estende para além do Direito". (LOSANO, 2007, p. 319). "Como dizemos nós juristas - em costumes, isto é em fatos coletivamente repetidos, repetidos porque sustentados por uma conviç̧ão sempre mais generalizada, e que na constância da repetição encontram sua eficácia vinculante, ou seja, sua normatividade". (GROSSI, 2011, p. 27).

16 "A Toscana. A partir mais ou menos do século XIII, a oligarquia urbana (comerciantes, burgueses) transforma os domínios senhoriais (os latifundia) que ela possui por herança ou adquire. Sobre essas terras, ela instala o "colonato parciário": colonos no lugar de servos. O colono recebe sua parte no produto; ele tem, portanto, interesse em produzir, mais que o escravo e o servo. O movimento que se produz então, e que produz uma nova realidade social não se baseia nem sobre a cidade (o urbano) considerada à parte, nem sobre o campo tomado isoladamente, mas sobre sua relação (dialética) no espaço, a partir de sua história. A burguesia urbana deseja ao mesmo tempo alimentar as pessoas da cidade, investir na agricultura, se apoiar no território inteiro, suprir o mercado de cereais, de lãs, de peles sobre seu controle. Então ela transforma o país e a paisagem [...] Na Toscana, e alhures à mesma época na França, não houve apenas produção material e aparição de formas sociais, ou, produção social de realidades materiais. O espaço produzido não foi nem rural, nem urbano, mas resultado de sua relação espacial engendrada. Causa e razão desta transformação: o crescimento das forças produtivas, as do artesanato, da indústria nascente, as da agricultura. Mas o crescimento não ocorre senão da relação "cidade-campo", e por consequência através dos grupos motores do desenvolvimento: a oligarquia urbana, uma fração de camponeses. Resultado: uma maior riqueza, logo um maior sobre produto, resultado que reage sobre suas condições. O luxo, a construção de palácios e monumentos permite aos artistas, e de início aos pintores, dizerem a seu modo o que se faz; fazer ver o que eles discernem. Eles descobrem, teorizam a perspectiva porque um espaço em perspectiva lhes é oferecido: porque esse espaço foi produzido. A obra e o produto só se distinguem através da análise retrospectiva. [...]. Ao fim desse processo emerge uma nova representação do espaço expressa pelos pintores, arquitetos e geômetras. O saber sai de uma prática, acrescentando-lhe a elaboração: formalização, encadeamento lógico". (LEFEBVRE, 2006, p. 70-71). 
uso (a cidade e a vida urbana, o tempo urbano) e o valor de troca (os espaços comprados e vendidos, o consumo dos produtos, dos bens, dos lugares e dos signos) ainda não aparecem em plena luz como na expansão das forças produtivas do capitalismo na modernidade (LEFEBVRE, 2006, p. 28).

As cidades retomaram seu desenvolvimento sem perder a relação entre cidade-campo, em perspectiva solidária, com prevalência do uso principal da cidade. A cidade aparece como obra - valor de uso e, o produto, como valor de troca:

As cidades apoiam as comunidades camponesas e a libertação dos camponeses, não sem se aproveitarem disso em seu próprio benefício. A própria cidade é uma obra, e esta característica contrasta com a orientação irreversível na direção ao dinheiro, na direção das trocas, na direção dos produtos. Com efeito a obra é valor de uso e o produto valor de troca. 0 uso principal da cidade, isto é das ruas e das praças, dos edifícios e dos monumentos, é a festa (que consome improdutivamente, sem nenhuma outra vantagem além do prazer e do prestígio, enormes riquezas em objetos e em dinheiro). Realidade complexa, isto é, contraditória. As cidades medievais, no apogeu de seu desenvolvimento, centralizam as riquezas; os grupos dirigentes investem improdutivamente uma grande parte dessas riquezas nas cidades que dominam (LEFEBVRE, 2006, p. 05).

A concepção da produção tripartite do espaço na concepção de Lefebvre (prática espacial, representações do espaço e espaços de representação) ligam a experiência expressa nas relações de produção do espaço da cidade comercial e do valor de uso na Idade Média Central. A prática insere o fazer cotidiano da vida na relação das atividades cidade-campo; os espaços de representação envolvem as partes e funções que compõem os elementos da cidade-campo e, as representações do espaço evidenciam-se nos costumes locais e de uma lex ${ }^{17}$ não desvinculada da realidade da cidade comercial, do valor de uso e de trocas $^{18}$.

\footnotetext{
17 A lex é realidade subjetivamente complexa, para a qual concorrem vários sujeitos: um sujeito determinante, o populus, que tem, com o próprio assentimento, uma função ativa, para cuja utilidade é promulgada e que depois é obrigado a observá-la; um segundo sujeito, o cientista-jurista, que dá a lex forma técnica e conteúdos; um terceiro sujeito, o príncipe que é chamado unicamente a conferir a sanção da sua autoridade. (GROSSI, 2014, p. 175).

${ }^{18}$ Karl Marx na obra "O capital", conceitua o que é mercadoria, valor de uso e valor de troca. Em síntese, as mercadorias são todos aqueles bens que perfazem as necessidades sociais e individuais e que por sua vez possuem duplo valor: valor de uso e valor de troca. O valor de uso é sempre medido pelo consumo (utilidade). O pequeno produtor rural, por exemplo, produz batatas, arroz, feijão e mandioca e outras culturas de subsistência simplesmente para satisfazer suas necessidades sem trocá-las ou vendê-las. Estará produzindo meramente valores de uso. No entanto, falta-lhe muitas outras coisas e precisa destas (roupas e panelas...). Tem e não precisa, precisa mas não tem! Resolver esta contradição é necessário. Indo ao mercado (comércio) entra numa relação social, local em que adquire o que não tem e precisa e
} 
A cidade que a idade média criou era a mediação entre as mediações, pois continha uma ordem próxima e a mantinha, sustentava relações de produção e propriedade, era o local de sua reprodução. A cidade mantinha relações na ordem distante que a sustentava, porém, projetava-se sobre o local e sobre o plano da vida imediata. Cidades italianas, flamengas, inglesas e francesas eram animadas e dominadas por mercadores e banqueiros como obra, significando bem mais valor de uso do que de valor de troca. Referida cidade continua a ser para a atualidade "modelo de uma realidade urbana onde o uso (a fruição, a beleza, o encanto dos locais de encontro) predomina sobre o lucro e o proveito, sobre o valor de troca, sobre os mercados e suas exigências e coações" (LEFEBVRE, 2006, P. 46-47).

Nesta perspectiva:

O dinheiro ${ }^{19}$ e a mercadoria ${ }^{20}$, ainda "in statu nasciendi" não forneciam apenas uma "cultura", mas um espaço. A originalidade da praça do mercado não foi oprimida pelo esplendor dos edifícios religiosos e políticos. A base da riqueza permaneceu a propriedade fundiária, a da terra. A revolução medieval faz entrar o comércio na cidade e o instala no centro do espaço urbano e transformado. A praça do mercado, difere da ágora como do fórum, livre de acesso, se abre para todas as partes do território circundante (que a cidade domina e explora), sobre a rede de estradas e caminhos (LEFEBVRE, 2000, p. 209).

Registra-se aqui que o capitalismo comercial e bancário, no apogeu das cidades medievais, já havia tornado móvel a riqueza e os circuitos de troca, com redes de transferência de dinheiro, porém, ainda havia a prevalência da agricultura sobre a indústria e da propriedade da terra pelos senhores feudais.

A ordem jurídico-política estava circunscrita não apenas na forma cotidiana de ordenação da vida da cidade e da realidade! Referida ordem também determinava a circulação da riqueza, de mercadorias, do ouro e das relações do poder político-econômico.

Foram as cidades mesmo anterior à industrialização que aceleraram o crescimento da

dispensa o que tem e não precisa. Em outras palavras, dispensa as 20 sacas de batatas e recebe as roupas e as panelas. Os produtos trocados tornaram-se mercadorias, pois, além de possuírem concretamente valores de uso, realizaram seu valor de troca. Foram realizadas as trocas e saciadas as necessidades. Entretanto, à primeira vista, os produtos trocados, nos parecem que foram medidos pela quantidade de um produto e a de outro. Será? O que há de realmente comum entre os objetos trocados? Há de comum o tempo de trabalho gasto para produzir determinado produto. O tempo de trabalho não aparece. O que aparece é a forma do valor (objeto que pode ser comercializado). (MARX, 1987, p 93).

19 "As moedas venezianas se difundiram em toda a Europa e na bacia do Mediterrâneo, servindo como instrumento comercial até 1797, quando Napoleão Invadiu e dissolveu a República Vêneta". (DAL RI JÚNIOR, 2014, p. 57).

20 "A mercadoria é antes de mais nada, um objeto externo que por suas propriedades satisfaz as necessidades humanas, sejam qual for a natureza; a origem delas provenha do estômago ou da fantasia. Não importa como a coisa satisfaça a necessidade humana, se diretamente como meio de subsistência, objeto de consumo, ou diretamente como meio de produção". (MARX, 1987, p. 41). 
produtividade e possibilitaram a arrancada para a indústria, concorrendo para a deterioração da centralidade e o caráter urbano das cidades (LEFEBVRE, 2006, p. 08).

\section{A CIDADE INDUSTRIAL E DA URBANIZAÇÃO}

Para Lefebvre a industrialização pressupõe a ruptura do sistema urbano preexistente. Sua tese funda-se em argumentos de que,

a cidade e a realidade urbana dependem do valor de uso. O valor de troca e a generalização da mercadoria pela industrialização tendem a destruir, ao subordiná-las a si, a cidade e a realidade urbana, refúgios do valor de uso, embriões de uma virtual predominância e de uma revalorização do uso (LEFEBVRE, 2006, p. 06).

O sistema urbano preexistente era o da sociedade medieval (o modo de produção feudal) que se estabeleceu no espaço anteriormente constituído, com seus castelos, monastérios, catedrais, comunidades camponesas e cidades, berço e arrancada da acumulação ${ }^{21}$ na Europa Ocidental.

Entretanto, na posição defendida por Lefebvre, a expansão das forças produtivas do capitalismo na modernidade criou seu próprio espaço, em que:

[...] a cidade gera algo de diferente, algo que a ultrapassa: no plano econômico, gera a indústria; no plano social, gera a propriedade de bens móveis (não sem transigir com as formas feudais de propriedade e de organização); no plano político, finalmente, gera o Estado. Esse o resultado histórico da primeira grande luta das classes e das formas sociais na Europa: cidade contra campos, burguesia contra feudalismo, propriedade de bens móveis e propriedade privada contra propriedade fundiária e comunitária (LEFEBVRE, 1972, p. 44).

Em sua teoria da produção do espaço, Lefebvre complementa a assertiva expressa, na forma seguinte:

O capitalismo e o neo-capitalismo produziram o espaço abstrato que contém o "mundo da mercadoria", sua "lógica" e suas estratégias à escala mundial, ao mesmo tempo que a potência do dinheiro e a do Estado político. Esse espaço abstrato apóia-se em enormes redes de bancos, centros de negócios de grandes unidades de produção. E também no espaço das auto-estradas, dos aeroportos, das redes de informação. Neste espaço, a cidade, berço da acumulação, lugar da riqueza, sujeito da história, centro do espaço histórico explodiu (LEFEBVRE, 2000, p. 51).

Importante registrar que para Lefebvre a prática social cria obras e produz coisas a

\footnotetext{
21 "A utilização da mais-valia como capital, a sua reconversão em capital, chama-se acumulação". (MARX, 1987, p. 189)
} 
partir do trabalho ${ }^{22}$. A produção no sentido marxista ultrapassa a oposição filosófica do "sujeito" e do "objeto", bem como as relações construídas pelos filósofos a partir desta separação. É o trabalho humano a origem e a fonte da produção - da racionalidade ativa da produção de obras e produtos. Aliás, sentido de produção que foi diluída pela ideologia produtivista, do economismo grosseiro e brutal na sociedade do capitalismo e do neocapitalismo que produziram o espaço abstrato que contém o mundo da mercadoria, ocultando a sua origem e fonte (LEFEBVRE, 2006, p. 64-65).

A urbanização e o urbano contêm o sentido da industrialização para Lefebvre. A produção industrial implica a urbanização: A produção industrial, após certo crescimento, produz a urbanização; fornece as condições desta e lhe abre possibilidades. A problemática se desloca e torna-se a problemática do desenvolvimento urbano (LEFEBVRE, 2006, p. 80).

A formação e a expansão dos centros urbanos são sínteses do movimento da sociedade capitalista contemporânea, ou seja, expressam, concomitantemente, a ordem e a desordem global, a acumulação da riqueza e a generalização da miséria, a concentração e a segregação. Enfim, o espaço urbano acaba por configurar-se "como lugar dos enfrentamentos e confrontações, unidade das contradições” (LEFEBVRE, 1999, p. 80).

A cidade política, comercial e do valor de uso "explode em pedaços"! O processo duplo (industrialização-urbanização) produz o duplo movimento, condensação-dispersão (estouro). É, portanto, em torno desse ponto que se situa a problemática atual da cidade e da realidade urbana (do urbano). (LEFEBVRE, 2006, p. 72).

Nesta perspectiva, a reprodução das relações de produção com a industrialização e urbanização, produziu um espaço em que:

O capitalismo de Estado em geral, têm a necessidade da cidade como centro (centro de decisões e centro também de riqueza, de informação, de organização do espaço). Ao mesmo tempo, fazem explodir e fragmentar-se e desaparecer a "cidade" como centro historicamente constituído, como centro político. A centralidade desmorona-se no seio do espaço que gera, quer dizer, no seio das relações de produção existentes e da sua reprodução (LEFEBVRE, 1973, p. 17-18).

Destaca-se que o centro inclui e atrai os elementos que o constituem como tal (as mercadorias, os capitais, as informações, etc.) e que em breve o saturam. A análise de Lefebvre se dirige no sentido de que o imenso processo do capitalismo se apoderou da cidade e fê-la explodir, gerando um espaço social a partir da indústria e da divisão técnica do trabalho,

\footnotetext{
$22 \mathrm{O}$ trabalho é independente de todas as formações sociais, condição da existência humana, necessidade natural de mediar a própria vida humana. (MARX, 1987, p. 46).
} 
aprofundando as contradições no/do espaço.

Santos, em perspectiva similar as categorias de análise de Lefebvre, atesta que o processo de produção, nos marcos da sociedade capitalista, expressa-se por meio de uma configuração específica do espaço social, abrangendo sua forma, função e estrutura ${ }^{23}$ pela qual se objetiva. O fenômeno da alienação objetivado no espaço social produz a percepção do espaço social, de igual forma, parcial, truncada, fragmentada e humanamente desvalorizada. $\mathrm{O}$ mercado e o espaço constituem forças modeladoras da sociedade, numa trama articulada de pontos que asseguram a produção e a reprodução de diferenças profundamente desiguais, contraditórias e alienadas (SANTOS, 2007b. p. 80).

A formação econômica e social moderna implica a dimensão representada pelo espaço. A produção social do espaço na modernidade realiza uma inversão de sentido na realidade até então predominante! A realidade urbana modifica as relações de produção, sem, aliás, ser suficiente para transformá-las. A realidade urbana se torna força produtiva, como a ciência. 0 espaço e a política do espaço "exprimem" as relações sociais, porém, reagem sobre elas (Lefebvre, 1999, p. 24).

O processo de urbanização difere do urbano. O urbano se constitui num processo inacabado, é o horizonte possível. O urbano realiza-se com a superação dos obstáculos que se apresentam na realidade.

A urbanização da sociedade sob o domínio do capital move-se no sentido de produzir a mercantilização da totalidade ${ }^{24}$ das relações e dos espaços.

O conceito de sociedade urbana destacado por Lefebvre difere do conteúdo produzido pela urbanização capitalista. A percepção destaque é que o avanço qualitativo da produção econômica proporcionado pelo processo de industrialização resultou num fenômeno qualitativamente novo: a urbanização da sociedade. Neste sentido:

a re-produção das relações de produção não coincide mais com a reprodução dos meios de produção; ela se efetua através da cotidianidade, através dos lazeres, da cultura, através da escola e da universidade, através das extensões e proliferações da antiga cidade, ou seja, através do espaço inteiro (LEFEBVRE, 1999, p. 47).

\footnotetext{
23 "A estrutura espacial, isto é, o espaço organizado pelo homem, é como as demais estruturas sociais, uma estrutura subordinada-subordinante. E como as outras instâncias, o espaço, embora submetido à lei da totalidade, dispõe de uma certa autonomia que se manifesta por meio de leis próprias, específicas de sua própria evolução". (SANTOS, Edusp, 2007b. p. 80).

${ }^{24} \mathrm{~A}$ ampliação e a complexificação do processo de produção estende-se à totalidade da sociedade, ou, ainda, à totalidade das relações sociais. (CARLOS, 2008).
} 
Com a globalização ${ }^{25}$ o espaço inteiro se transforma em lugar da reprodução das relações sociais de produção. O espaço moderno e urbanizado apresenta-se, ao mesmo tempo, homogêneo e fragmentado, separado e ordenado. Os diferentes espaços de produção e reprodução social se encontram articulados e estabelecem relação de dependência entre si. O tempo e o espaço onde acontece a reprodução da força de trabalho encontram-se separados e reunidos ao mesmo tempo. Essa é a dinâmica que compõe o esquema da reprodução do espaço capitalista: Esses espaços separados da produção, como se fosse possível aí ignorar o trabalho produtivo, são lugares da recuperação. Tais lugares, aos quais se procura dar um ar de liberdade e de festa, que se povoam de signos que não têm a produção e o trabalho por significado, estão estreitamente ligados ao trabalho produtivo (LEFEBVRE, 2008, p. 50).

Lefebvre qualifica a teorização da produção do espaço sob a hegemonia do capital globalizado. A produção da cidade-mercadoria, enquanto expressão da captura e remodelagem do espaço segundo a lógica do capital mundial, impõe a necessidade de tornar "invisíveis" as contradições sociais gritantes decorrentes desse mesmo processo. A fragmentação e a produção do espaço, tornado mercadoria em escala planetária, provocam profundas e múltiplas contradições. Não é possível reduzir o espaço a uma localização geográfica, ou mesmo às relações de posse e propriedade. A dinâmica impressa no espaço social, ao mesmo tempo, em que se apresenta como local concreto da ação realizada, abre a possibilidade da manifestação de novas ações ${ }^{26}$.

Em síntese, Lefebvre ao mesmo tempo que aprofunda a análise da produção do espaço

25 Milton Santos, na análise sobre a produção do espaço, utiliza as noções de verticalidades e horizontalidades, a fim de expor a dinâmica que se impõe no cenário da globalização. Primeiramente, identifica a definição das verticalidades enquanto um conjunto de pontos que formam um "espaço de fluxos", que, por sua vez, são determinados por atores do "tempo rápido" que hegemonizam o processo. Por conseguinte, esse "espaço de fluxos" expressa, "[...] um sistema dentro da totalidade-espaço, já que para efeitos dos respectivos atores o que conta é, sobretudo, esse conjunto de pontos adequados às tarefas produtivas hegemônicas, características das atividades econômicas que comandam este período histórico". (SANTOS, 2009b. p. 106).

${ }^{26}$ As ações das atividades produtivas hegemônicas atuam verticalmente no sentido de unificação e homogeneização do tempo real, representado pelas frações de territórios, a subordinação do "relógio universal" determinado pela temporalidade das empresas globais. Como contraponto à lógica hegemônica das verticalidades econômicas, Santos aponta a existência das "horizontalidades", sendo estas identificadas com o "espaço banal", o espaço de "todos" corresponde à possibilidade de manifestação de integrações solidárias, cuja natureza pode pertencer a diferentes campos, seja econômico, seja social, cultural ou geográfico. Na horizontalidade do espaço banal, é possível a integração de ações desenvolvidas por diferentes atores, com seus diferentes "tempos", em um espaço comum. As horizontalidades, nas palavras do autor, são as contrarracionalidades, ou seja, "[...] formas de convivência e de regulação criadas a partir do território e que se mantêm nesse território a despeito da vontade de unificação e homogeneização, características da racionalidade hegemônica típica das verticalidades". (SANTOS, 2009, p. 109). 
gerado no seio da sociedade industrial de da urbanização, defende a luta pela cidade voltada à apropriação coletiva, à cidade como direito a vida urbana transformada e renovada. Ao lado da revolução econômica e revolução política (democracia e autogestão) é necessário uma revolução cultural permanente capaz de transformar a produção do espaço enquanto práxis de recuperação do urbano - simultaneidade do encontro, da cidade como obra e fruição do direito de uso, da troca não apenas subordinada ao comércio e ao lucro.

\section{CONSIDERAÇÕES FINAIS}

O estudo pretendeu dimensionar e problematizar a história do espaço jurídico-político da cidade antiga, medieval e moderna no contexto da Europa.

As contribuições da teoria da produção do espaço jurídico-político da cidade, a partir de elementos da análise de Henri Lefebvre, serviram de marco referencial estruturante para situar a ordenação da cidade política, a cidade comercial, a cidade industrial e da urbanização enquanto espaços socialmente produzidos.

Os resultados do estudo confirmaram que a produção do espaço jurídico-político da cidade não se processa de modo separado dos aspectos da vida social, econômica e cultural.

A cidade política tinha seu centro organizacional forte representados em seus monumentos e lugares (ágora, acrópole). Havia a plenitude do espaço político (aquele da cité da Cidade-Estado) instaurado no espaço natural.

A Cidade medieval foi profundamente marcada pela produção do espaço comercial e do valor de uso. Ao mesmo tempo que a troca comercial tornava sustentável as cidades medievais, havia a valorização efetiva do uso dos bens e lugares da cidade. Quase tudo circulava e se voltava ao desenvolvimento local da própria cidade e seu entorno.

A cidade industrial e da urbanização marcou a ruptura do sistema urbano preexistente. Provocou mudanças significativas no sistema produtivo e nas relações de trabalho. O valor de troca tomou maior força em relação ao valor de uso e comércio de bens. A convergência dos encontros diminui. A urbanização serve e impulsiona a reprodução das relações sociais de produção realizadas para atender aos processos advindos das formas dos capitais se reproduzirem.

Complementarmente, ao abordar a contemporaneidade do capitalismo financeiro em o Direito à cidade, Lefebvre ultrapassa a sociedade industrial em sua análise. A abordagem de sua dialética implica a vinculação espaço-tempo-sociedade. 
O local é a realidade onde se produz o espaço cotidiano e assume uma dimensionalidade da produção material da vida mediada pela ordenação jurídico-político da economia, do social e da cultura.

Os aspectos jurídicos e políticos não se apresentam dissociados do espaço geográfico e do contexto social articulado ao modo de produção vigente num determinado tempo e espaço.

A reconfiguração da produção do espaço a partir do estado moderno implicou em análise não desvinculada das relações de produção e reprodução imersas no contexto do surgimento da sociedade industrial e capitalista.

A centralidade do poder ante a soberania dos Estados-Nações passou significativamente a incidir sobre a vida e ordenação das cidades e seus municípios e/ou comunidades territoriais.

Por fim, não se pode negar de que a produção jurídico-política do espaço encontra forte imbricação entre a cidade, o município e o Estado em suas múltiplas dimensionalidades.

\section{REFERÊNCIAS BIBLIOGRÁFICAS}

ARISTÓTELES. A Política. Trad. Nestor Silveira Chaves. 2. ed. Bauru, SP: Edipro, 2009.

BOBBIO, Norberto. Teoria das formas de governo. Trad. Sérgio Bath. 7. ed. Brasília: UnB, 1994.

CARLOS, Ana Fani A. A (re)produção do espaço urbano. São Paulo: Edusp, 2008.

GOTTDIENER, Mark. A produção social do espaço urbano. Trad. de Geraldo Gerson de Souza. São Paulo: USP, 1993.

GROSSI, Paolo. A ordem jurídica medieval. Trad. de Denise Rossato Agostinetti. São Paulo: Martins Fontes, 2014.

KONDER, Leandro. O que é dialética. São Paulo: Brasiliense, 2008.

LE GOFF, J. O apogeu da cidade medieval. Tradução de Antônio de Pádua Danesi. São Paulo: Martins Fontes, 1992.

Por amor às cidades. Trad. Reinaldo Carmello Corrêa de Moraes. São Paulo: Fundação Editora da Unesp, 1998.

LEFEBVRE, Henri. O pensamento marxista e a cidade. Póvoa de Varzim: Tipografia Camões, 1972.

A re-produção das relações de produção. Trad. Antônio Ribeiro e M. Amaral. Porto: Publicações Escorpião, 1973.

"Space: social produt and use value". In.: GOTTDIENER, Mark. A produção social do espaço urbano. Trad. de Geraldo Gerson de Souza. São Paulo: USP, 1993.

A revolução urbana. Belo Horizonte: UFMG, 1999.

$\mathrm{O}$ direito à cidade. Trad. Rubens Eduardo Frias. São Paulo: Centauro, 2006.

A produção do espaço. Trad. Doralice Barros Pereira e Sérgio Martins (do original: La Production de l'espace. 4. ed. Paris: Éditions Anthropos, 2000). Primeira versão início - fev. 
2006.

Espaço e política. Trad. Margarida Maria de Andrade e Sérgio Martins. Belo Horizonte: UFMG, 2008.

LOSANO, Mário G. Os grandes sistemas jurídicos: introdução aos sistemas jurídicos europeus e extra-europeus. Trad. Marcelo Varejão. São Paulo: Martins Fontes, 2007.

MARX, Karl. O capital. 11. ed. São Paulo: Berthand Brasil, 1987.

PLATÃO. A República. Trad. Anna Amaral Del Almeida Prado. 2. ed. São Paulo: Martins Fontes, 2014.

SANTOS, Milton. O espaço do cidadão. 7. ed. São Paulo: Edusp, 2007b.

Por uma economia política da cidade. 2. ed. São Paulo: Edusp, 2009b.

Por uma geografia nova. 6. ed. São Paulo: Edusp, 2008b.

SCHMIDT, Christian. A teoria da produção do espaço de Henri Lefebvre: em direção a uma dialética tridimensional. Trad. Marta Inez Medeiros Marques; Marcelo Barreto. GEOUSP espaço e tempo, São Paulo, n. 32, p. 89-109, 2012.

VICENTINHO, Cláudio. História geral. São Paulo: Scipione, 1997.

Trabalho enviado em 19 de maio de 2017.

Aceito em 19 de outubro de 2017. 